\title{
A study of maternal near miss cases in tertiary health centre in north India
}

\section{Lovepreet Kaur*, Manjit Kaur Mohi, Balwinder Kaur, Beant Singh}

Department of Obstetrics and Gynecology, Government Medical College, Patiala, Punjab, India

Received: 13 June 2018

Revised: 25 June 2018

Accepted: 05 July 2018

\section{*Correspondence: \\ Dr. Lovepreet Kaur, \\ E-mail: 1vprt.kr@gmail.com}

Copyright: () the author(s), publisher and licensee Medip Academy. This is an open-access article distributed under the terms of the Creative Commons Attribution Non-Commercial License, which permits unrestricted non-commercial use, distribution, and reproduction in any medium, provided the original work is properly cited.

\section{ABSTRACT}

Background: Maternal near miss is defined as woman who nearly died but survived a complication that occurred during pregnancy, childbirth or within 42 days of termination of pregnancy.

Methods: It was one-and-a-half-year prospective study from April 2016 to September 2017 conducted in the department of Obstetrics and Gynecology, Government Medical College, Patiala. The causes of maternal near miss based on WHO 2010 Near Miss criteria were studied.

Results: In the present study out of total deliveries of 6166, there were 5461 live births and 123 maternal near miss cases which were included based on WHO 2010 maternal near miss approach. The maternal near miss incidence ratio (MNMR) in present study is 22.5. Literature reports the similar trends and MNMR varies between 15 to 40 per 1000 live births. Maternal near miss to mortality ratio is 1.89:1 in the present study.

Conclusions: The most common direct cause for maternal near miss is hemorrhage. Severe preeclampsia is one of the easiest identifiable and avoidable factors for preventing maternal death. Studying near miss in detail allows us proper assessment of opportunities that were missed, analyzing the gaps and patient care related factors and helps to develop an audit system for maternal care.

Keywords: Causes, Maternal near miss, WHO criteria

\section{INTRODUCTION}

Maternal near miss is defined as woman who nearly died but survived a complication that occurred during pregnancy, childbirth or within 42 days of termination of pregnancy. Maternal mortality is one of the most important indicators used for assessing maternal health. According to WHO, a maternal death is defined as the death of a woman while pregnant or within 42 days of termination of pregnancy, irrespective of the duration and site of pregnancy, from any cause related to or aggravated by the pregnancy or its management but not from accidental or incidental causes. ${ }^{1}$ Despite being caused by pregnancy related events, these deaths do not count as maternal deaths in routine civil registration system. An alternative concept of the maternal death was included in ICD-10, in order to capture these delayed deaths that occur between 6 weeks and 1-year post-partum. ${ }^{1}$

About $80 \%$ of maternal deaths are due to direct causes i.e. obstetric complications of pregnancy, labour and puerperium or inappropriate and inadequate interventions, treatment and/ or referral. Remaining $20 \%$ of maternal deaths are due to indirect causes like, the result of pre-existing diseases or disease that developed during pregnancy which are not due to direct obstetric cause but are aggravated by the physiological cause of pregnancy. Causes of maternal mortality being: Hemorrhage, hypertension, eclampsia, obstructed labour, abortion, etc. Anemia being one of the major indirect 
cause along with other indirect causes such as hepatitis, cardiovascular disease, endocrine diseases and metabolic systems, infections such as tuberculosis, malaria and increasing number of infections like HIV/ AIDS. ${ }^{2}$

Social factors contributing to maternal mortality in India are: Age at child birth, parity, too close pregnancies, family size, malnutrition, poverty, illiteracy, ignorance and prejudices, lack of maternity services, shortage of health man-power, delivery by untrained dais, poor environmental sanitation, poor communication and transport facilities, social customs, etc. ${ }^{3}$

Reduction in maternal mortality is one of the Millennium Development Goals (MDG 5) with target 5A that calls for reduction of maternal mortality by 3 quarters between 1990 and $2015 .^{3}$

In any setting women who develop severe acute morbidity during pregnancy share many pathological and circumstantial factors related to their condition. While some of them die, a proportion of women narrowly escape deaths which come under maternal near miss category. Many maternal deaths occur at home or in transit which makes it difficult to obtain complete information regarding maternal death and its cause especially in developing countries. Near miss cases survive these complications and therefore can provide vital information. By evaluating these cases with severe maternal outcome, one can get to know about processes in health system (or lack of them) to deal with maternal morbidities. ${ }^{3}$

The near miss criteria developed by WHO technical group have been tested and validated as being able to provide robust and reliable data. The WHO working group has also developed a set of indicators for the assessment of quality of care within a health care facility or the health system. In order to ensure that the evaluation of quality of care with the near-miss approach is comprehensive, a set of process indicators is developed which is considered to be beneficial and feasible method of auditing the quality of maternal health care. ${ }^{3}$

\section{METHODS}

\section{Inclusion criteria}

The present study was one-and-a-half-year prospective study from April 2016 to September 2017 conducted in the department of Obstetrics and Gynecology, Government Medical College, Patiala. The study was conducted on patients admitted in labour room including referred, emergency and booked admission. Women with severe complications of pregnancy/ labour/ puerperium irrespective of gestational age as per WHO near miss criteria were identified and studied. The eligibility was not restricted by the gestational age at which complications occurred i.e. women having abortions or ectopic pregnancy as well as medical conditions and presenting with any of the inclusion criteria were eligible. The first step in implementing the near miss approach was to systematically identify women with severe complications of pregnancy.

\section{Exclusion criteria}

Women that developed those conditions unrelated to pregnancy i.e. not during pregnancy or 42 days after termination of pregnancy were excluded.

\section{RESULTS}

Table 1: Characteristics of patients.

\begin{tabular}{|lll|}
\hline Age & Number & Percentage \\
\hline$<20 y r$ & 04 & 3.3 \\
\hline $20-35$ & 118 & 95.9 \\
\hline$>35$ & 01 & 0.8 \\
\hline Parity & & \\
\hline Primipara & 39 & 31.7 \\
\hline Multipara & 84 & 68.3 \\
\hline Gestational age & & \\
\hline$<13$ weeks & 15 & 12.2 \\
\hline $13-28$ weeks & 22 & 17.8 \\
\hline$>28$ weeks & 52 & 42.4 \\
\hline Postnatal & 34 & 27.6 \\
\hline Mode of delivery & & \\
\hline Vaginal & 20 & 24.7 \\
\hline $\begin{array}{l}\text { Caesarean section } \\
\text { Laparotomy for rupture } \\
\text { uterus/ hysterectomy }\end{array}$ & 35 & 43.2 \\
\hline Laparotomy for ectopic & 15 & 9.9 \\
\hline Classical caesarean & 3 & 12.2 \\
\hline
\end{tabular}

Table 1 shows the distribution of near miss cases according to different age groups. Maximum number of cases fall between 20-35 years of age making constituting $95.9 \%$ of total near miss cases in present study which is the common reproductive age group. Multipara forming majority of cases i.e. $68.3 \%$ as the number of complications increase in multipara patients. In first trimester there were $12.2 \%$ cases of ruptured ectopic with hemoperitoneum who underwent laparotomy. In second there were $17.8 \%$ cases. Majority of cases were of hemorrhage $(26 \%)$ out of which, abruptio placentae $(15.62 \%)$ followed by placenta previa $(9.3 \%)$, placenta accreta $(6.25 \%)$, placenta percreta $(3.125 \%)$. Third trimester had $42.4 \%$ cases which had eclampsia (18.7\%) and severe preeclampsia with jaundice (5.6\%). Sepsis was seen in $9.8 \%$ cases. Respiratory distress in $4 \%$, rupture uterus in $4 \%$ cases. $24.7 \%$ patients had vaginal deliveries, $43.2 \%$ underwent Lower segment caesarean section, $9.9 \%$ underwent laparotomy for rupture uterus, $12.2 \%$ underwent laparotomy for ruptured ectopic pregnancy and $3.7 \%$ underwent classical caesarean section. Remaining 42 patients were referred from other centres due to postpartum hemorrhage, acute uterine 
inversion and non-availability of blood bank and ventilator.

Table 2: Distribution of maternal near miss according to complication of pregnancy.

\begin{tabular}{|lll|}
$\begin{array}{l}\text { Complication of } \\
\text { pregnancy }\end{array}$ & $\begin{array}{l}\text { No. of near miss } \\
\text { cases N=123 }\end{array}$ & Percentage \\
\hline $\begin{array}{l}\text { Anaemia without } \\
\text { hemorrhage }\end{array}$ & 42 & 34.1 \\
\hline Hemorrhage & 32 & 26 \\
\hline Eclampsia & 23 & 18.7 \\
\hline Sepsis & 12 & 9.8 \\
\hline Liver disease & 7 & 5.7 \\
\hline Rupture uterus & 5 & 4 \\
\hline Respiratory disease & 5 & 4 \\
\hline Obstructed labour & 4 & 3.2 \\
\hline Heart disease & 2 & 1.6 \\
\hline
\end{tabular}

Most common direct complicating factor being hemorrhage $26 \%$, eclampsia $18.7 \%$, sepsis $9.8 \%$, rupture uterus $4 \%$ (rupture uterus was present in 2 cases of grand multipara and 3 cases had more than 2 previous LSCS) and obstructed labour $3.2 \%$.

Table 3: Management, clinical and laboratory-based identification of near miss cases.

\begin{tabular}{|c|c|c|}
\hline Intervention & Number & Percentage \\
\hline Massive blood transfusion & 67 & 54.47 \\
\hline Magnesium sulphate therapy & 27 & 21.95 \\
\hline Laparotomy & 23 & 18.69 \\
\hline ICU admission & 18 & 14.63 \\
\hline Higher antibiotic use & 17 & 13.82 \\
\hline Inotrope use & 15 & 12.19 \\
\hline Peripartum hysterectomy & 4 & 3.25 \\
\hline \multicolumn{3}{|l|}{ Clinical criteria } \\
\hline $\begin{array}{l}\text { Loss of consciousness }>12 \\
\text { hours }\end{array}$ & 23 & 18.7 \\
\hline Shock & 17 & 13.8 \\
\hline Clotting failure & 16 & 13 \\
\hline $\begin{array}{l}\text { Respiratory rate }<6 / \text { min or } \\
>40 / \text { min }\end{array}$ & 10 & 8.1 \\
\hline Oliguria & 9 & 7.3 \\
\hline $\begin{array}{l}\text { Jaundice in presence of } \\
\text { preeclampsia }\end{array}$ & 7 & 5.7 \\
\hline \multicolumn{3}{|l|}{ Laboratory findings } \\
\hline $\begin{array}{l}\text { Oxygen saturation }<90 \% \\
\text { for }>60 \mathrm{~min}\end{array}$ & 18 & 14.6 \\
\hline $\begin{array}{l}\text { Acute thrombocytopenia } \\
<50,000\end{array}$ & 7 & 5.6 \\
\hline S. bilirubin $>6 \mathrm{mg} / \mathrm{dl}$ & 7 & 5.6 \\
\hline S. Creatinine $>3.5 \mathrm{mg} / \mathrm{dl}$ & 1 & 0.8 \\
\hline
\end{tabular}

Among the indirect causes anaemia $34.1 \%$ was leading cause. Out of this iron deficiency anaemia was seen in $88 \%$ cases and $12 \%$ cases had other types of anaemia like megaloblastic and thalassemia minor. Respiratory disease
4\%, liver disease $5.7 \%$ (mainly hepatic encephalopathy) and heart disease $1.6 \%$ (1 patient had dilated peripartum cardiomyopathy and 1 patient was revived from sudden cardiac arrest).

Table 3 depicts various interventions done in near miss cases in present study, with massive blood transfusion given to $54.47 \%$ of cases, which included 15 cases of ruptured ectopic with hemoperitoneum, 17 cases of caesarean section, 2 cases of acute uterine inversion, 19 cases of atonic PPH and 2 cases of traumatic PPH and 12 cases of very severe anaemia with failure. ICU admission needed by $14.63 \%$ cases, ionotropic support (due to shock) in form of dopamine and noradrenaline needed by $12.19 \%$ cases, $18.69 \%$ cases underwent laparotomy (15 cases due to ruptured ectopic with hemoperitoneum, 4 cases due to rupture uterus followed by repair, 3 cases due to rectus sheath hematoma and 1 post LSCS case of ileal resection followed by ileostomy) and $3.25 \%$ underwent hysterectomy (1 case due to placenta percreta, 2 cases due to placenta accreta and 1 case due to rupture uterus beyond repair. (The total of this table does not sum up to 123 as one patient underwent more than one form of treatment.)

Distribution of cases according to clinical criteria include maximum cases of loss of unconsciousness for more than 12 hours i.e. $18.7 \%$, shock $13.8 \%$, clotting failure $13 \%$, respiratory rate $<6 / \mathrm{min}$ or $>40 / \mathrm{min}$ in $8.1 \%$, oliguria in $7.3 \%$ and jaundice with severe preeclampsia in $5.7 \%$ cases. Distribution of near miss cases according to laboratory criteria, and oxygen saturation $<90 \%$ for $>60$ $\min$ in $14.6 \%$ cases. $5.6 \%$ cases with acute thrombocytopenia and serum bilirubin $>6 \mathrm{mg} / \mathrm{dl}$ and serum creatinine $>3.5 \%$ in $0.8 \%$ cases.

\section{DISCUSSION}

The study conducted for a period of one and a half year included 123 patients categorized as maternal near miss who reported to the labour room of department of obstetrics and gynecology, Govt. Medical College, Patiala. In the present study out of total deliveries of 6166, there were 5461 live births and 123 maternal near miss cases which were included based on WHO 2010 maternal near miss approach. The maternal near miss incidence ratio (MNMR) in present study is 22.5. Literature reports the similar trends and MNMR varies between 15 to 40 per 1000 live births. ${ }^{4-6}$ Maternal near miss to mortality ratio is $1.89: 1$ in the present study, which means for every 2 lives saved there was 1 maternal death. The ratio is similar to a study conducted in Bastar district of Chhattisgarh, India which had near miss to mortality ratio of $2: 1{ }^{7}$ Study of near miss morbidity done in western Rajasthan also had a near miss mortality ratio of $2: 1 .^{8}$. Present results are also similar to those of African countries where range is $2-11: 1 .^{9}$ 
Table 4: Distribution of clinical criteria for identification of near miss cases.

\begin{tabular}{|llll|}
\hline Study & Brace et al & Das et al & Present study \\
\hline Clinical criteria & & & \\
\hline Loss of consciousness $>$ 12hour & $13 \%$ & $11.3 \%$ & $18.7 \%$ \\
\hline Shock & $3 \%$ & $53 \%$ & $13.8 \%$ \\
\hline Clotting failure & $7.74 \%$ & $4 \%$ & $13 \%$ \\
\hline Gasping & $8 \%$ & $4 \%$ & $9.8 \%$ \\
\hline Respiratory rate $<6 /$ min or $>40 /$ min & $9 \%$ & $17.7 \%$ & $8.1 \%$ \\
\hline Oliguria & $10 \%$ & $11.8 \%$ & $7.3 \%$ \\
\hline Jaundice in presence of preeclampsia & $2.3 \%$ & $3.6 \%$ & $5.7 \%$ \\
\hline
\end{tabular}

Table 4 shows a comparison of clinical criteria for identification of maternal near miss cases. ${ }^{4,10}$ Study by Brace et al reported loss of consciousness $>12$ hours in $13 \%$ cases, shock in $3 \%$ cases, clotting failure in $7.74 \%$, gasping in $8 \%$, respiratory rate $<6 /$ min or $>40 / \mathrm{min}$ in $9 \%$ cases, oliguria in $10 \%$ and jaundice in presence of preeclampsia in $2.3 \%$ cases. Das et al reported loss of consciousness in $18.7 \%$ cases, shock in $53 \%$, clotting failure in $4 \%$, gasping in $8 \%$ cases, respiratory rate problems in $17.7 \%$, oliguria in $11.8 \%$ and jaundice in presence of preeclampsia in $3.6 \%$ cases. Present study concluded loss of consciousness in $18.7 \%$ cases, shock in $13.8 \%$, clotting failure in $13 \%$, gasping in $9.8 \%$ cases, respiratory rate $<6 / \mathrm{min}$ or $>40 / \mathrm{min}$ in $8.1 \%$, oliguria in $7.3 \%$ and jaundice in presence of preeclampsia in $5.7 \%$ cases. Results of present study matched with Brace et al and Das et al except shock was in $13.8 \%$ cases which is one fourth of the cases in Das et al. Clotting failure in $13 \%$ cases which is almost 3 times the study by Das et al.

Table 5: Management based criteria and intervention performed.

\begin{tabular}{|llll|}
\hline $\begin{array}{l}\text { Criteria } \\
\text { Massive blood }\end{array}$ & $\begin{array}{l}\text { Das } \\
\text { et al }\end{array}$ & $\begin{array}{l}\text { Rajakumari } \\
\text { et al }\end{array}$ & $\begin{array}{l}\text { Present } \\
\text { study }\end{array}$ \\
\hline $\begin{array}{l}\text { transfusion } \\
\text { Magnesium }\end{array}$ & $38 \%$ & $31 \%$ & $54.47 \%$ \\
\hline ICU admission therapy & $18 \%$ & - & $21.95 \%$ \\
\hline Higher antibiotic use & $10 \%$ & $8.48 \%$ & $13.82 \%$ \\
\hline Inotrope use & $54.7 \%$ & - & $12.19 \%$ \\
\hline $\begin{array}{l}\text { Peripartum } \\
\text { hysterectomy }\end{array}$ & $5.21 \%$ & $3.53 \%$ & $3.25 \%$ \\
\hline Dialysis & $1 \%$ & $1.06 \%$ & $0.8 \%$ \\
\hline
\end{tabular}

Table 5 shows the intervention done and management in MNM cases. Study by Das et al reported massive blood transfusion in $38 \%$ cases, magnesium sulphate therapy in $18 \%$ cases, ICU admission in $2.8 \%$ cases, higher antibiotic uses in $10 \%$ cases, peripartum hysterectomy in $5.21 \%$ and dialysis in $1 \%$ cases. In the present study, massive blood transfusion was in $54.47 \%$ patients, magnesium sulphate therapy in $21.95 \%$, ICU admission in $14.63 \%$, higher antibiotic uses in $13.82 \%$, ionotrope use in $12.19 \%$, peripartum hysterectomy in $3.25 \%$ and dialysis in $0.8 \%$ patients. The results of present study matched with Das et al and differed in two parameters i.e. ICU admissions were 7 times more in present study and ionotrope use was one fourth of Das et al, Rajakumari et al reported blood transfusion in $31 \%$, ICU admission in $73.49 \%$, higher antibiotic use in $8.48 \%$, peripartum hysterectomy in $3.53 \%$ and dialysis in $1.06 \% .^{11}$

Table 6: Laboratory based criteria for identification of near miss cases.

\begin{tabular}{|lll|}
\hline $\begin{array}{l}\text { Criteria } \\
\begin{array}{l}\text { Oxygen saturation } \\
<90 \% \text { for }>60 \mathrm{~min}\end{array}\end{array}$ & $\begin{array}{c}\text { Das et al } \\
\text { < }\end{array}$ & Present study \\
\hline $\begin{array}{l}\text { Acute thrombocytopenia } \\
<50,000\end{array}$ & $1.26 \%$ & $5.6 \%$ \\
\hline S. Bilirubin $>6 \mathrm{mg} / \mathrm{dl}$ & $13.7 \%$ & $5.6 \%$ \\
\hline S. Creatinine $>3.5 \mathrm{mg} / \mathrm{dl}$ & $11.8 \%$ & $0.8 \%$ \\
\hline
\end{tabular}

Table 6 shows laboratory-based criteria for identification of MNM. Study by Das et al (2014) reported $8.21 \%$ cases with oxygen saturation $<90 \%$ for $>60 \mathrm{~min}$, acute thrombocytopenia in $1.26 \%$, serum bilirubin $>6 \mathrm{mg} / \mathrm{dl}$ in $13.7 \%$ and serum creatinine $>3.5 \mathrm{mg} / \mathrm{dl}$ in $11.8 \%$. The present study reported oxygen saturation $<90 \%$ for $>60$ minutes in $14.6 \%$ cases, acute thrombocytopenia in $1.26 \%$ cases, serum bilirubin $>6 \mathrm{mg} / \mathrm{dl}$ in $5.6 \%$ and serum creatinine $>3.5 \mathrm{mg} / \mathrm{dl}$ in $0.8 \%$ cases. Results matched with Das et al with difference in Serum bilirubin parameter which was $13.7 \%$ in Das et al and $5.6 \%$ in present study. Also, serum creatinine parameter was much less in the present study $0.8 \%$ as compared to Das et al which had reported $11.8 \%$ cases.

\section{CONCLUSION}

The most common direct cause for maternal near miss is hemorrhage. Severe preeclampsia is one of the easiest identifiable and avoidable factors for preventing maternal death. Regular blood pressure monitoring at every antenatal visit along with urine complete examination for sugar and albumin serves as a baseline marker and can predict about the state of patient. Obstructed labour is still a major problem being encountered these days. Plotting a partograph when a patient enters active phase of labour is very important and helps to decide about any action that 
needs to be taken and save the maternal and neonatal morbidity. The need for identifying the patient conditions and deciding for the referral on time and to the right centre is a critical step towards saving a maternal death. The core of the health system should emphasize on 'when to refer' and 'where to refer' policy. Studying near miss in detail allows the proper assessment of opportunities that were missed, analyzing the gaps and patient care related factors and helps to develop an audit system for maternal care. Managing a near miss case is a team work and prompt and objective intervention can avert a maternal death.

\section{Funding: No funding sources}

Conflict of interest: None declared

Ethical approval: The study was approved by the Institutional Ethics Committee

\section{REFERENCES}

1. WHO (2005), Improving maternal, newborn and child health in the South-East Asia Region, New Delhi.

2. WHO (1998), World Health Report 1998, Life in the 21st century, a Vision for all, Report of Director General, WHO.

3. Govt. of India (2013), Special Bulletin on Maternal Mortality in India 2010-12, SRS, Dec. 2013, Office of Registrar General of India.

4. Brace V, Penney G, Hall M. Quantifying severe maternal morbidity: a Scottish population study. BJOG. 2004;111:481.

5. Say L, Souza JP, Pattinson RC. WHO working group on maternal mortality and morbidity classifications.
Maternal near miss- towards a standard tool for monitoring quality of maternal health care. Best Pract Res Clinical Obstet Gynecol. 2009;23:287-96.

6. Souza JP, Cecatti JG, Parpinelli MA, Serruya SJ, Amaral E. Appropriate criteria for identification of near miss maternal morbidity in tertiary care facilities: a cross sectional study. BMC Pregnancy Childbirth. 2007;7(20):1-8.

7. Bansal M, Lagoo J, Pujari K. Study of near miss cases in obstetrics and maternal mortality in Bastar, Chhattisgarh, India. Int J Reprod Contracep Obstet Gynecol. 2017 Feb 23;5(3):620-3.

8. Kalra P, Kachhwaha CP. Obstetric near miss morbidity and maternal mortality in a Tertiary Care Centre in Western Rajasthan. Indian J Public Health. 2014 Jul 1;58(3):199.

9. Maternal near miss operational guidelines. December 2014, ministry of health and family welfare, Government of India.

10. Pandey A, Das V, Agarwal A, Agrawal S, Misra D, Jaiswal N. Evaluation of obstetric near miss and maternal deaths in a tertiary care hospital in north India: Shifting focus from mortality to morbidity. J Obstet Gynecol India. 2014 Dec 1;64(6):394-9.

11. Rajakumari P, Manonmani. Maternal near Miss: an indicator of Maternal health. IOSR J Dental Med Sci. 2017;3(16):9-15.

Cite this article as: Kaur L, Mohi MK, Kaur B, Singh B. A study of maternal near miss cases in tertiary health centre in north India. Int J Reprod Contracept Obstet Gynecol 2018;7:3239-43. 